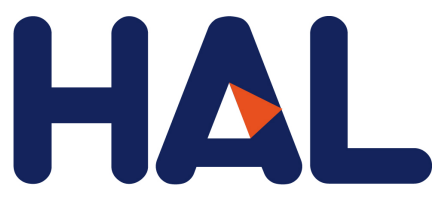

archives-ouvertes

\title{
Visible-Light Emulsion Photopolymerization of Acrylates and Methacrylates: Mechanistic Insights and Introduction of a Simplified Sulfur-Based Photoinitiating System
}

Daniel Subervie, Frédéric Le Quéméner, Rémi Canterel, Pierre-Yves Dugas, Olivier Boyron, Jacques Lalevée, Elodie Bourgeat-Lami, Muriel Lansalot, Emmanuel Lacote

\section{To cite this version:}

Olivier Boyron, Daniel Subervie, Frédéric Le Quéméner, Rémi Canterel, Pierre-Yves Dugas, et al.. Visible-Light Emulsion Photopolymerization of Acrylates and Methacrylates: Mechanistic Insights and Introduction of a Simplified Sulfur-Based Photoinitiating System. Macromolecules, American Chemical Society, In press, 10.1021/acs.macromol.0c01692 . hal-03142669

HAL Id: hal-03142669

https://hal-univ-lyon1.archives-ouvertes.fr/hal-03142669

Submitted on 16 Feb 2021

HAL is a multi-disciplinary open access archive for the deposit and dissemination of scientific research documents, whether they are published or not. The documents may come from teaching and research institutions in France or abroad, or from public or private research centers.
L'archive ouverte pluridisciplinaire HAL, est destinée au dépôt et à la diffusion de documents scientifiques de niveau recherche, publiés ou non, émanant des établissements d'enseignement et de recherche français ou étrangers, des laboratoires publics ou privés. 


\section{Visible-Light Emulsion Photopolymerization of}

\section{Acrylates and Methacrylates: Mechanistic Insights}

\section{and Introduction of a simplified Sulfur-based}

\section{Photoinitiating System}

Daniel Subervie, ${ }^{a, b}$ Frédéric Le Quéméner, ${ }^{b}$ Rémi Canterel, ${ }^{a, b}$ Pierre-Yves Dugas, ${ }^{b}$ Olivier Boyron, ${ }^{b}$ Jacques Lalevée, ${ }^{* c}$ Elodie Bourgeat-Lami, ${ }^{* b}$ Muriel Lansalot, ${ }^{* b}$ Emmanuel Lacôte ${ }^{* a}$ $\mathrm{a}$

Univ Lyon, Univ Claude Bernard Lyon 1, CNRS, CNES, ArianeGroup, LHCEP; Bât. Raulin, 2 rue Victor Grignard, F-69622 Villeurbanne, France; e-mail: emmanuel.lacote@univ-lyon1.fr

${ }^{\mathrm{b}}$ Univ Lyon, Université Claude Bernard Lyon 1, CPE Lyon, CNRS, UMR 5265, Chemistry, Catalysis, Polymers and Processes (C2P2), 43 Bd du 11 Novembre 1918, F-69616 Villeurbanne, France; e-mail: muriel.lansalot@univ-lyon1.fr, elodie.bourgeat-lami@univ-lyon1.fr

${ }^{\mathrm{c}}$ Université de Haute-Alsace, Université de Strasbourg, CNRS, IS2M UMR 7361, F-68100 Mulhouse, France 
Table of Contents (TOC) graphic for Table of Contents use only

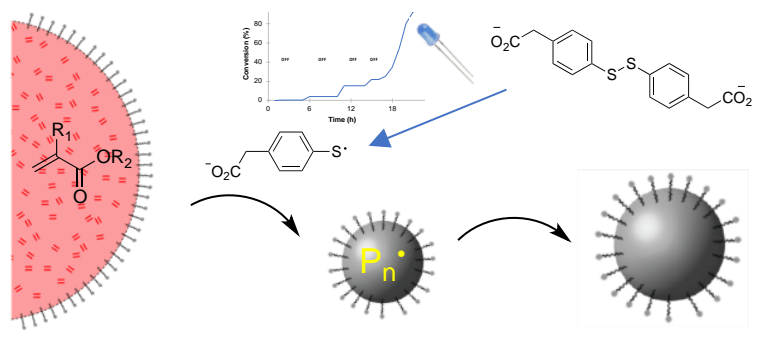

ABSTRACT The emulsion photopolymerization under visible-light of acrylate and methacrylate monomers is reported. We previously introduced a NHC-borane-based system that was efficient for the emulsion photopolymerization of styrene (Acridine Orange (AO)/disulfide/NHC-borane). This system relies on the disulfide photoreduction from the excited $\mathrm{AO}$, followed by $\mathrm{H}$-atom abstraction from the NHC-Borane by the thiyl radical generated from the disulfide, eventually forming initiating NHC-Boryl radicals. For the photopolymerization of (meth)acrylates, the Boron-based photoinitiating system was simplified, as under LED illumination the water-soluble disulfide alone is able to generate thiyl radicals that could initiate the polymerizations. With this disulfide/blue light system, MMA efficiently polymerized in emulsion, with solids contents up to $40 \%$. The simplified system led to smaller particles than the full photo-initiating Boron-based system, but the latter gave slightly better particle size distributions. Compared to styrene, the particle sizes attained for MMA were generally smaller. The disulfide photo-initiator gives access to a wide range of poly(meth)acrylic latexes, but it does not initiate the photopolymerization of styrene. We suggest that the propagation rate prevails on monomer solubility in the case of (meth)acrylates, which explains the efficiency of the 
photopolymerization with a much weaker initiating system. The method can also lead to the production of random copolymer latexes, such as $\mathrm{P}(\mathrm{MMA}-\mathrm{co}-\mathrm{St})$ as well as the film-forming $\mathrm{P}(\mathrm{MMA}-\mathrm{co}-\mathrm{BA})$. That the disulfide is able to lead to the former further supports the predominant role of the propagation rate on the polymerization. Finally, the polymerization allows for temporal control. It proceeds under light, and stops in the dark.

\section{Introduction}

Photopolymerization in dispersed media ${ }^{1}$ is gaining increasing attention because it offers the advantages related to the use of dispersed media - use of a safe and green solvent when water is involved; high molar mass polymers; final products obtained as fluid latexes even for high solids

contents $-{ }^{2}$ while at the same time benefitting from an external handle over the reactivity. ${ }^{3,4}$ However, because light, especially the shorter waves UV required for photoinitiations, is scattered by larger objects and because most of the existing photo-initiators (PIs) are lipophilic, mostly photopolymerizations in mini- $-^{5-12}$ or micro ${ }^{13-17}$ emulsions had until recently been considered.

However, emulsion polymerizations require that the initiation step takes place in the continuous aqueous phase, in the presence of micrometric monomer reservoir droplets. This has severely limited progress in emulsion photopolymerizations, particularly so because UVs are scattered in the medium. ${ }^{1}$ Recent progress has been made possible by the use of visible light, which

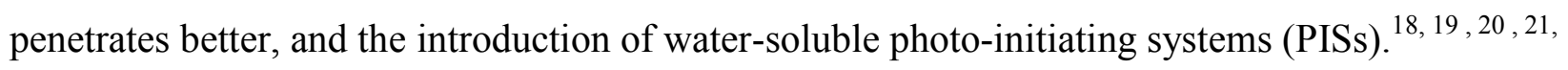
${ }^{22}$ In our initial contribution we introduced a Boron-based co-initiator that could be activated upon $\mathrm{H}$ transfer to a photogenerated thiyl radical. This allowed us to produce polymer particles 
with maximum diameter of $300 \mathrm{~nm} .{ }^{18}$ We now report the extension of our process to methyl methacrylate (MMA) and other (meth)acrylic monomer compositions. We show that (meth)acrylates are compatible with a simplified Sulfur-based PIS. Mechanistic investigations have been carried out to explain this behavior.

\section{Materials and Methods}

\section{Materials}

4-mercaptobenzylacetic acid (97\%), potassium bis(trimethylsilylamide) (95\%), 1,2,4-triazole (98\%), methyl iodide (99.5\%), dimethyl sulfoxide (DMSO, 99\%), tetrahydrofuran (99.5\% over molecular sieves), acridine orange (AO, 75\%), styrene (99\%), methyl methacrylate (MMA, 99\%), $n$-butyl acrylate (BA, 99\%), 2-ethylhexyl methacrylate (EHMA, 98\%), $n$-butyl methacrylate (BMA, 99\%), sodium dodecyl sulfate (SDS, 99\%) and sodium carbonate (99\%) were purchased from Sigma-Aldrich and used as received. Triazolylidene borane $\mathbf{1}$ was prepared

according to the literature (see Figure 1). ${ }^{23}$ Pentane (99\%, Aldrich) and dichloromethane (DCM, 99\%, Aldrich) were purified with a SPS800 MBraun and degassed prior to use. Chloroform-d and dimethyl sulfoxide- $\mathrm{d}_{6}$ were purchased from Sigma-Aldrich. Deionized water (PureLab Classic UV, Elga Lab Water) was used for latex synthesis. Thin layer chromatography (TLC) was performed on Merck 60 F254 silica gel, and Merck Gerduran SI 60 A silica gel (35-70 mm) was used for column chromatography. The LED ribbon used was purchased from LED's Go (Ref RUB_THP_250_NW_BN).

\section{Methods}


Synthesis of 2,2'-(disulfanediylbis(4,1-phenylene))diacetic acid (2). 4-mercaptobenzylacetic acid (1.1 g) was introduced in a two-neck flask connected to a bleach trap, closed with a septum and flushed with argon. DMSO (3.5 g) was added and the reaction mixture was stirred under argon for 2 days. Excess solvents and byproducts $\left(\mathrm{Me}_{2} \mathrm{~S}\right.$ and $\left.\mathrm{H}_{2} \mathrm{O}\right)$ were removed under reduced pressure giving a yellow oil. DCM $(10 \mathrm{~mL})$ was then added together with water $(20 \mathrm{~mL})$, and the dispersion obtained was stirred vigorously. The precipitate was filtered, washed with water $\left(2 \times 10 \mathrm{~mL}\right.$ ) and dried at $70{ }^{\circ} \mathrm{C}$ to afford 2 (see Figure 1). Yield: $85 \% .{ }^{1} \mathrm{H}$ NMR $(300 \mathrm{MHz}$, DMSO-d $\left.\mathrm{d}_{6}\right): \delta(\mathrm{ppm})=7.46(\mathrm{~d}, 4 \mathrm{H}$, arom. $), 7.26\left(\mathrm{~d}, 4 \mathrm{H}\right.$, arom.), $3.55\left(\mathrm{~s}, 4 \mathrm{H}, \mathrm{CH}_{2}\right) \cdot{ }^{13} \mathrm{C}$ NMR (75.4 MHz, DMSO-d $\left.\mathrm{d}_{6}\right): \delta(\mathrm{ppm})=172.9(\mathrm{C}=\mathrm{O}), 135.2(\mathrm{C}$ arom. $), 134.4(\mathrm{C}$ arom. $), 131.0(\mathrm{CH}$ arom.), 127.9 ( $\mathrm{CH}$ arom.), $39.0\left(\mathrm{CH}_{2}\right)$. HRMS calc. $357.0231\left([\mathrm{M}+\mathrm{Na}]^{+}\right)$, found 357.0225 .

General procedure for the emulsion polymerizations. The emulsion polymerization reactions were conducted in a $250 \mathrm{~mL}$ double wall reactor mounted with a mechanical stirrer equipped with a glass anchor. The LED ribbon was coiled around the reactor. The emission spectrum was measured in our labs (Figure S1).

In a typical procedure using the "full photoinitiator" system, acridine orange (75\% pure, $8.8 \mathrm{mg}$, $2.5 \times 10^{-5} \mathrm{~mol}$ ) was dissolved in $25 \mathrm{~mL}$ of monomer. Then $1 \mathrm{~mL}$ of this solution was added to monomer to get $25 \mathrm{~g}$ of the dispersed phase. The continuous phase was composed of $100 \mathrm{~mL}$ of water, SDS, triazolylidene borane 1, disulfide 2 and sodium carbonate. Both solutions were degassed by nitrogen bubbling prior to their transfer with a cannula to the reactor previously purged with nitrogen. The solution was then stirred 5 min in order to form an emulsion, then light was switched on, setting the time zero of the reaction. All the experiments performed with the full PIS are gathered in Table 1. 
In a typical procedure using the "disulfide 2 photoinitiator" system, a solution of $25 \mathrm{~g}$ of monomer was degassed to obtain the dispersed phase. The continuous phase was composed of $100 \mathrm{~mL}$ of water, SDS, disulfide 2 and sodium carbonate. Both solutions were degassed by nitrogen bubbling prior to their transfer with a cannula to the reactor previously purged with nitrogen. The solution was then stirred $5 \mathrm{~min}$ in order to form an emulsion, then light was switched on, setting the time zero of the reaction. All the experiments performed with the disulfide 2 only are gathered in Table 2.

When KPS was used as an initiator, it was dissolved in the continuous phase composed of 100 $\mathrm{mL}$ of water containing SDS. The dispersed phase was composed of MMA. Both solutions were degassed by nitrogen bubbling prior to their transfer with a cannula to the reactor previously purged with nitrogen and heated to $70^{\circ} \mathrm{C}$. The complete addition set the time zero of the reaction.

Samples were periodically withdrawn from the reactor to determine the particle size by DLS and the monomer conversion by gravimetric analysis according to the formula:

$$
\text { Conversion }=\frac{m_{0}-m_{t}}{m_{0}} * 100=\frac{m_{\text {polymer }}}{m_{0}} * 100=\frac{\frac{m_{\text {dry }}}{m_{\text {aliquot }}}-\tau_{N V}}{\tau_{\text {solid }}} * 100
$$

where $m_{0}$ is the initial mass of monomer $(\mathrm{g}) ; m_{t}$ the reacted mass of monomer at time $t(\mathrm{~g}) ; m_{d r y}$ is the mass of dry aliquot $(\mathrm{g}) ; m_{\text {aliquot }}$ is the mass of aliquot $(\mathrm{g}) ; \tau_{N V}$ the non-volatile content apart polymer (i.e. initiating system and surfactant); $\tau_{\text {solid }}$ the theoretical solids content at $100 \%$ conversion (initial mass of monomer/overall system mass).

\section{Characterization techniques}


- Nuclear magnetic resonance (NMR). NMR spectra were recorded on a Bruker DRX300. Chloroform $(\delta=7.26 \mathrm{ppm})$ and dimethyl sulfoxide $(\delta=2.50 \mathrm{ppm})$ were used as internal standards for ${ }^{1} \mathrm{H}$ and ${ }^{13} \mathrm{C}$ NMR. ${ }^{11} \mathrm{~B}$ chemicals shifts are relative to $\mathrm{Et}_{2} \mathrm{O} \cdot \mathrm{BF}_{3}(0 \mathrm{ppm})$.

- Dynamic light scattering (DLS). DLS was used to measure the particle size (average hydrodynamic diameter, $\mathrm{Z}_{\mathrm{av}}$ ) and the dispersity of the samples (PdI) at $25^{\circ} \mathrm{C}$ using a Zetasizer Nano Series (Nano ZS) from Malvern Instruments. Before measurements, the latex was diluted with water. The data were collected at $173^{\circ}$ scattering angle using the fully automatic mode of the Zetasizer system.

-(Cryo-)transmission electron microscopy ((Cryo-)TEM). The polymer particles were imaged at

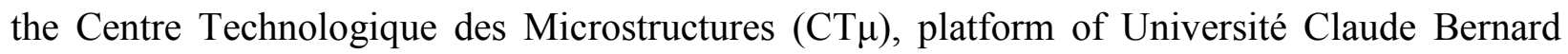
Lyon 1. For TEM, a drop of the diluted latex was deposited on a carbon/Formvar ${ }^{\circledR}$-coated copper grid, and the water was allowed to evaporate. The analysis was carried out at room temperature with a Philips CM120 microscope operating at an accelerating voltage of $80 \mathrm{kV}$. Cryo-TEM observations were carried out for some samples to prevent deformation/degradation of the particles at room temperature. Thin liquid films of the suspensions were formed on holey carbon films (Quantifoil R2/1) and quench-frozen in liquid ethane. The specimens were observed at low temperature $\left(-170^{\circ} \mathrm{C}\right)$ with a Philips $\mathrm{CM} 120$ microscope operating at $120 \mathrm{kV}$, under low dose conditions. The number-average $\left(D_{\mathrm{n}}\right)$ and the weight-average $\left(D_{\mathrm{w}}\right)$ diameters, and the diameter dispersity $\left(D_{\mathrm{w}} / D_{\mathrm{n}}\right)$ of the polymer particles were determined directly on the (cryo)TEM micrographs according to $D_{n}=\frac{\sum n_{i} D_{i}}{\sum n_{i}}$ and $D_{w}=\frac{\sum n_{i} D_{i}^{4}}{\sum n_{i} D_{i}^{3}}$, where $n_{i}$ is the number of particles with diameter $D_{i}$. A minimum of 200 particles was counted for each batch. 
- Laser flash photolysis (LFP). LFP nanosecond experiments were carried out at Institut de Science des Matériaux de Mulhouse (IS2M), using a Q-switched nanosecond Nd/YAG laser $\left(\lambda_{\text {exc }}=355 \mathrm{~nm}, 9 \mathrm{~ns}\right.$ pulses; energy reduced down to $10 \mathrm{~mJ}$ ) from Continuum (Minilite) and an analyzing system consisting of a ceramic xenon lamp, a monochromator, a fast photomultiplier and a transient digitizer (Luzchem LFP 212). This set-up has already been presented in detail elsewhere. ${ }^{24}$

\section{Results and Discussion}

As a follow-up to our previous work on visible light styrene emulsion photopolymerization, ${ }^{18}$ we used our three-component system to investigate the MMA homo-photopolymerization in emulsion. The PIS (also referred as "full system") is a three-component system that includes acridine orange $(\mathrm{AO})$ as sacrificial photo-single electron transfer reagent, the water-soluble triazolylidene-borane $\mathbf{1},{ }^{23}$ and aryl disulfide $\mathbf{2}$ (Figure 1). Aryl disulfide $\mathbf{2}$ has a $p \mathrm{~K}_{\mathrm{a}}=3.8$ and is therefore negatively charged and water-soluble under the reaction conditions $(\mathrm{pH} \sim 8)$. Its reaction with $\mathrm{AO}$ generates a thiyl radical that can abstract a $\mathrm{H}$ atom from $\mathbf{1}$. The resulting $N$ heterocyclic carbene (NHC)-Boryl radical 1 1 is the initiating radical. In a typical polymerization (Entry 1, Table 1), a solution of AO and MMA was added to the aqueous phase containing NHCborane 1, disulfide 2 and sodium dodecyl sulfate (SDS, at its critical micelle concentration, 8 $\mathrm{mM}$ ) and the resulting mixture was stirred via a stirring anchor. AO was initially solubilized in the monomer to prevent any premature activation of the disulfide. While soluble in both solvents, AO prefers water and will partition accordingly ${ }^{18}$ thus leading to initiation in the water phase, as customary for emulsion polymerizations. 


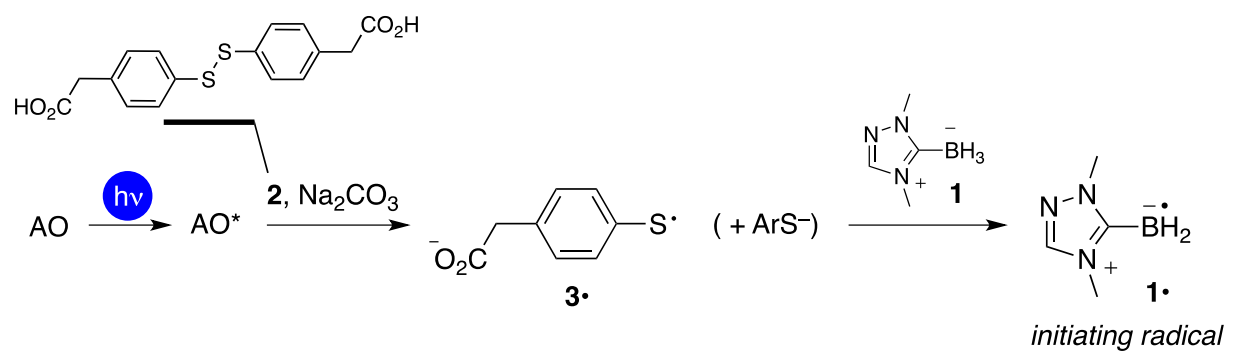

Figure 1. Formation of Boron-centered radicals in water via visible light irradiation (blue in that case). The three-component system is a PIS for emulsion photopolymerization under blue light.

Complete conversion was achieved after $4 \mathrm{~h}$ of irradiation (Table 1, Entry 1 and Figure 2, orange curve). No coagulum was observed and the latex obtained was highly stable. When compared to what was observed with styrene, the photopolymerization rate was higher with MMA under identical reaction conditions (Figure S2). The average particle size measured by dynamic light scattering (DLS) was $90 \mathrm{~nm}$ with a PdI of 0.09. Cryo-transmission electron microscopy (cryoTEM) analysis showed however that the particle size distribution was large $\left(D_{\mathrm{w}} / D_{\mathrm{n}}=1.37\right)$, with a significantly smaller number-average diameter $\left(D_{\mathrm{n}}\right)$ of $54 \mathrm{~nm}$ compared to DLS (Figure 2, left). A similar size difference between DLS and TEM analyses was observed in our previous work and was attributed to the large particle size distribution (PSD). Indeed, in a polydisperse sample, DLS is biased toward larger objects at the expense of smaller ones.

Table 1. Visible-light Emulsion Photopolymerizations of MMA with the NHC-Borane based PIS.

\begin{tabular}{|c|c|c|c|c|c|c|c|c|c|}
\hline Entry $^{\mathrm{a}}$ & $\begin{array}{l}\text { [SDS] } \\
(\mathrm{x} \mathrm{CMC})\end{array}$ & Time (h) & $\begin{array}{l}\text { Conv. } \\
(\%)\end{array}$ & $\begin{array}{l}D_{\mathrm{h}} \\
(\mathrm{nm})^{\mathrm{b}}\end{array}$ & $\mathrm{PdI}^{\mathrm{b}}$ & $\begin{array}{l}\mathrm{N}_{\mathrm{p}} \\
\left(10^{17} \mathrm{~cm}^{-3}\right)^{\mathrm{b}}\end{array}$ & $\begin{array}{l}D_{\mathrm{n}} \\
(\mathrm{nm})^{\mathrm{c}}\end{array}$ & $D_{\mathrm{w}} / D_{\mathrm{n}}{ }^{\mathrm{c}}$ & $\begin{array}{l}\mathrm{N}_{\mathrm{p}} \\
\left(10^{17} \mathrm{~cm}^{-3}\right)^{\mathrm{c}}\end{array}$ \\
\hline 1 & 1 & 4 & 100 & 90 & 0.09 & 4.9 & 54 & 1.37 & 20.5 \\
\hline
\end{tabular}




$\begin{array}{llllllllll}2 & 0.25 & 7.5 & 89 & 154 & 0.05 & 0.8 & 128 & 1.17 & 1.5 \\ 3 & 0.5 & 5 & 100 & 110 & 0.06 & 2 & 66 & 1.45 & 11.5 \\ 4 & 1.5 & 2.5 & 100 & 72 & 0.1 & 8 & 34 & 1.50 & 81 \\ 5 & 2 & 2.25 & 100 & 60 & 0.08 & 15 & 35 & 1.37 & 74 \\ 6^{\mathrm{d}} & 2 & 2.25 & 100 & 74 & 0.12 & 10 & 30 & 1.62 & 159 \\ 7^{\mathrm{e}} & 2 & 3 & 100 & 86 & 0.07 & 8 & 59 & 1.49 & 79 \\ 8^{\mathrm{f}} & 0.75 & 0.2 & 100 & 89 & 0.01 & 5 & 76 & 1.35 & 7 \\ 9^{\mathrm{f}} & 1 & 0.2 & 100 & 80 & 0.01 & 6 & 72 & 1.09 & 8 \\ 10^{\mathrm{f}} & 2 & 0.2 & 100 & 106 & 0.2 & 0.3 & 64 & 1.05 & 12 \\ 11^{\mathrm{g}} & 1 & 5.5 & 94 & 117 & 0.1 & 2 & 30 & 2.62 & 110 \\ 12^{\mathrm{h}} & 1 & 1.75 & 100 & 71 & 0.1 & 9 & 36 & 1.59 & 67 \\ 13^{\mathrm{i}} & 1 & 1.5 & 100 & 114 & 0.03 & 2 & 86 & 1.14 & 5 \\ 14^{\mathrm{j}} & 1 & 18 & 5.5 & - & - & - & - & - & -\end{array}$

\footnotetext{
${ }^{a}$ Conditions: a solution of AO $\left(10^{-5} \mathrm{M}, 1 \mathrm{~mol} \%\right.$ with regard to 1) and MMA was added to the aqueous phase containing the surfactant $(\operatorname{SDS}), \mathbf{1}\left([\mathbf{1}]=10^{-3} \mathrm{M}\right), \mathbf{2}\left(5 \times 10^{-4} \mathrm{M}, 50 \mathrm{~mol} \%\right.$ with regard to $\mathbf{1})$, and sodium carbonate $\left(10^{-3} \mathrm{M}\right)$. Unless otherwise specified, the solids content was fixed at $20 \%$; ${ }^{b}$ Hydrodynamic diameter, polydispersity index and number of particles determined by DLS; ${ }^{c}$ Number-average diameter, size dispersity and number of particles determined by TEM; ${ }^{d}$ Solids content was $26 \%$; ${ }^{e}$ Solids content was $31 \%$; ${ }^{f}$ Thermal initiation $\left([\mathrm{KPS}]=4.6 \times 10^{-3} \mathrm{M}\right){ }^{g}{ }^{g}$ Same conditions as entry 1 except without $\mathrm{AO} ;{ }^{h}$ Same conditions as entry 1 except without NHC-borane; ${ }^{i}$ Same conditions as entry 1 except without NHC-borane and without $\mathrm{AO} ;{ }^{j}$ Same conditions as entry 1 except without disulfide.
} 

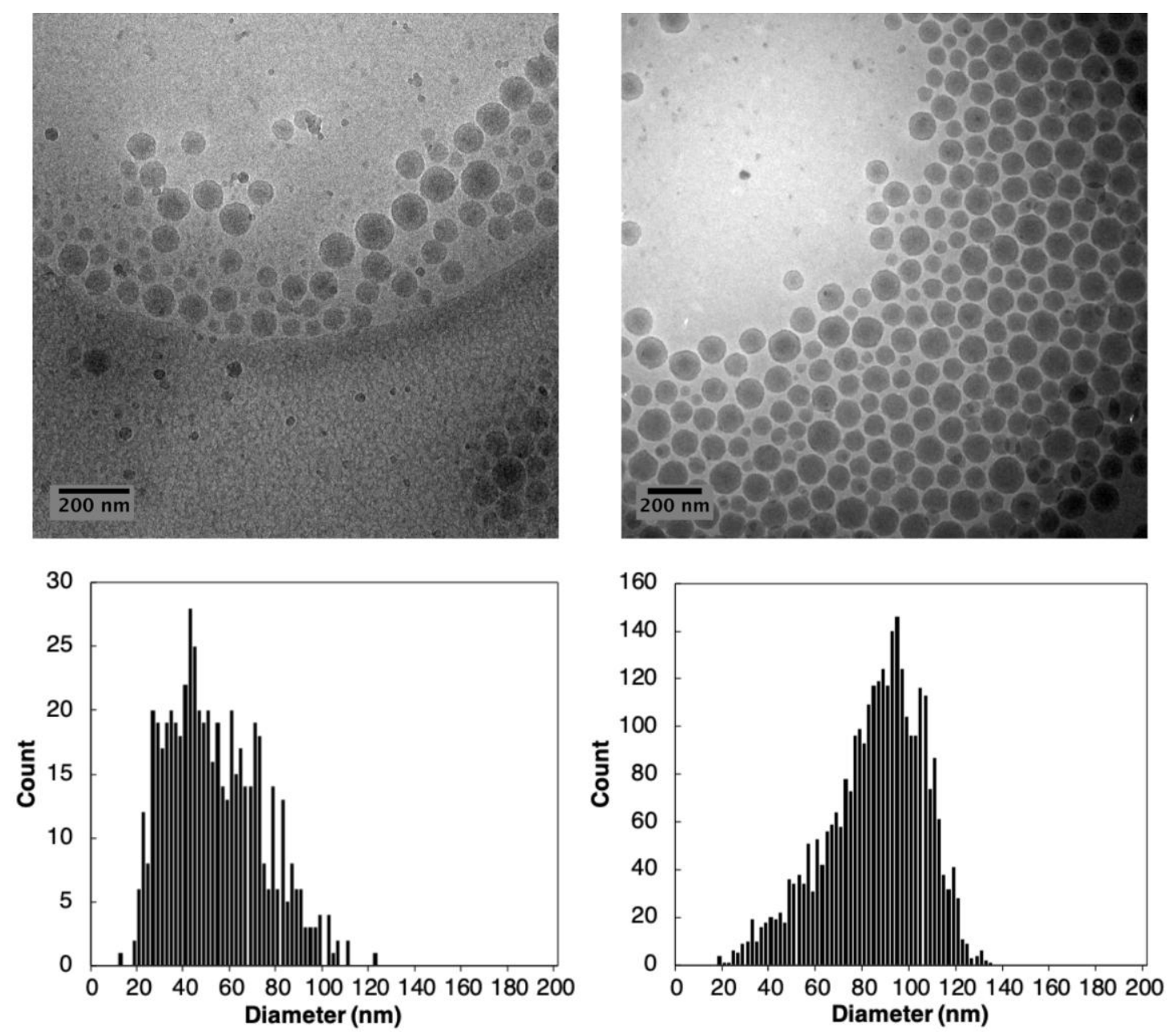

Figure 2. Cryo-TEM images and particle size distributions of the latexes obtained in the conditions described in Table 1, entries 1 (full system, left) and 13 (disulfide only, right).

A gradual increase of the surfactant concentration led to a decrease of $D_{\mathrm{n}}$ from $128 \mathrm{~nm}$ at $0.25 \mathrm{CMC}$ to $35 \mathrm{~nm}$ at $2 \mathrm{CMC}$ (Entries 2-5). The polymerizations were gradually faster (from $7.25 \mathrm{~h}$ to $2.75 \mathrm{~h}$ to reach full conversion, see Figure 3). A narrower particle size distribution was obtained below the $\mathrm{CMC}\left(D_{\mathrm{w}} / D_{\mathrm{n}}=1.17\right.$ at $0.25 \mathrm{CMC}$, entry 2$)$. Above the CMC the PSD was broader $\left(D_{\mathrm{w}} / D_{\mathrm{n}}=1.37\right.$ at $2 \mathrm{CMC}$, entry 5$)$. However, the fact that the PSD remained broad below the $\mathrm{CMC}$ is in contrast to what was observed for styrene. ${ }^{18}$ The second noticeable difference is 
that the particle sizes of PMMA were also much smaller than those of PS at the same surfactant concentration.

MMA is a more hydrophilic monomer than styrene (solubility in water $15 \mathrm{~g} \mathrm{~L}^{-125}$ vs $0.45 \mathrm{~g} \mathrm{~L}^{-1} 26$ at $50{ }^{\circ} \mathrm{C}$, respectively). This likely leads to the nucleation of more particles, since the initiation takes place in water. The higher polymerization rate observed for MMA therefore fits with the smaller particle size, and the higher number of particles $\left(N_{\mathrm{p}}=20 \times 10^{17} \mathrm{~cm}^{-3}\right.$ vs $2 \times 10^{17}$ for polystyrene at $1 \mathrm{CMC}$ ), although care should be taken when considering this last number because of the large PSD. Both monomers led to broad PSDs above CMC, but the average particle size (either from DLS or cryo-TEM analysis) was smaller for the PMMA latex. The large PSDs in the emulsion photopolymerization of styrene at or above the CMC were explained by a low flux of initiating radicals. ${ }^{18}$ The three-component photoinitiating system generates radicals rather slowly leading to the continuous formation of new particles. This is even more significant with MMA, which is more soluble in water than styrene and all the more prone to homogeneous nucleation. As a consequence, MMA leads to high particle size distributions also below the CMC.

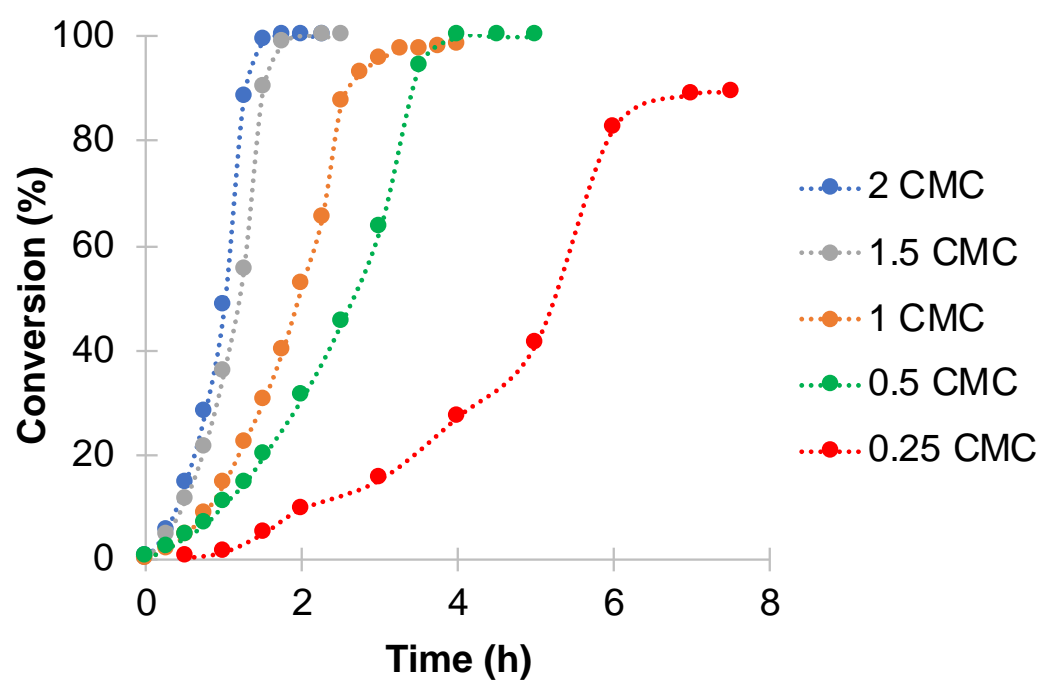


Figure 3. Conversion profiles of the emulsion photopolymerizations of MMA for different surfactant concentrations (full system, see Table 1, entries 1-5 for conditions).

Higher solids contents were examined next, at a surfactant concentration of 2 CMC (Entries 6-7). Increasing the initial amount of MMA without varying the other parameters led to a reduction of the polymerization rate ( $2.3 \mathrm{~h}$ for $26 \%$, entry 6 , and $3 \mathrm{~h}$ for $31 \%$, entry 7 ). The PSD was still very broad, but overall the high solids content-latexes were stable.

Finally, we compared our system with classical thermal polymerization conditions. Three KPSinitiated emulsion polymerizations of MMA were carried out at surfactant concentrations of 0.75, 1 and 2 CMC (Table 1, entries 8-10). The thermal polymerizations reached completion 10 times faster than the photopolymerizations and the PSD was narrower. As expected, the particle size slightly decreased with the increase of the surfactant concentration, from $76 \mathrm{~nm}$ at 0.75 CMC (entry 8 ) to $64 \mathrm{~nm}$ at $2 \mathrm{CMC}$ (entry 10). In contrast to styrene for which the thermal initiation always led to smaller particles, ${ }^{18}$ the "thermal" PMMA particle size above the CMC was twice as large as the size obtained from photoinitiated systems (64 nm vs $35 \mathrm{~nm}$ at 2 CMC) and similar below the CMC.

To shed some more light on the system, we carried out additional control experiments (Entries 11-14 and Figure 3). Without the dye, the polymerization plateaued at $94 \%$ conversion after 5.5 h, (entry 11). The particle size determined by cryo-TEM was slightly smaller $(30 \mathrm{~nm})$ and the PSD was significantly larger $\left(D_{\mathrm{w}} / D_{\mathrm{n}}=2.6\right.$ against 1.37$)$. Surprisingly, removing the NHC-borane strongly accelerated the polymerization, which reached $100 \%$ conversion after only $1.75 \mathrm{~h}$ (entry 12). The particle size and PSD remained roughly the same as with the NHC-Borane, however. When only the disulfide was kept as the PIS (entry 13), the polymerization was even faster but 
delivered much larger ( $86 \mathrm{~nm}$ by cryo-TEM, see Figure 4$)$ and less polydisperse particles $\left(D_{\mathrm{w}} / D_{\mathrm{n}}\right.$ $=1.14)$. Finally, in the absence of disulfide the polymerization failed (entry 14).

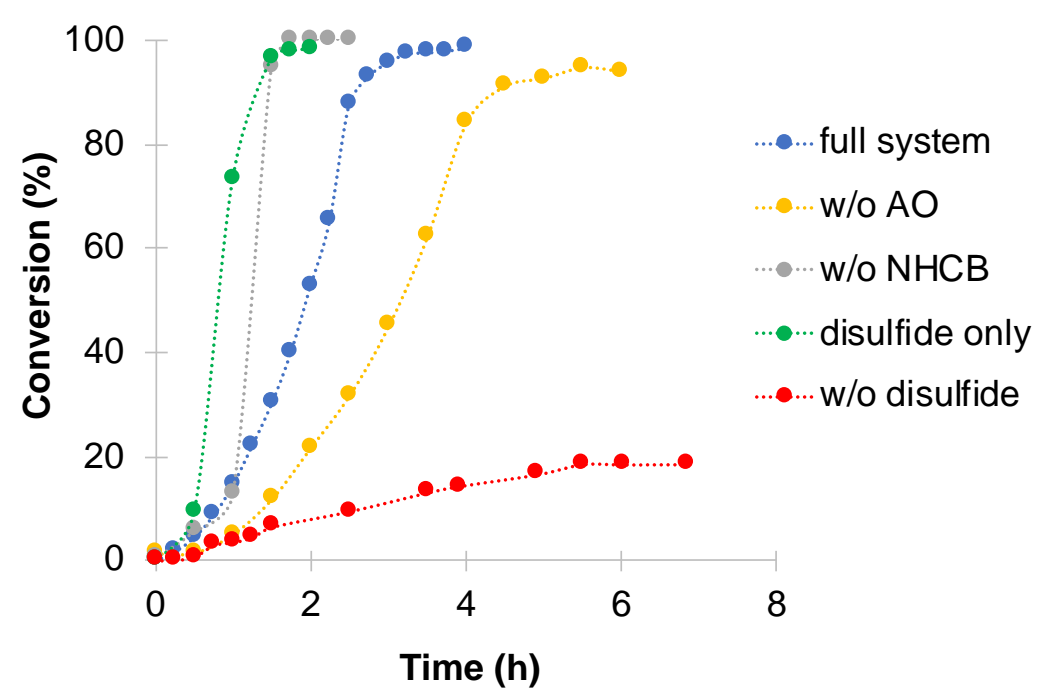

Figure 4. Conversion profiles of the photopolymerizations during control experiments (see Table 1, entries 1 and 11-14 for the conditions).

In summary of the control experiments, the polymerization outcome is significantly affected by nature of the PIS, in particular by the nature and efficiency of production of the initiating radicals (vide infra). The most striking result is that contrary to what was the case with styrene, the thiyl radicals formed directly by homolytic cleavage of disulfide 2 are efficient initiators. In other words, $\mathbf{2}$ is an excellent photoinitiator under visible light irradiation, away from its maximum absorption peak in the UV region. To the best of our knowledge, only one other group reported a similar behavior. ${ }^{27}$

These results were however clearly surprising. In the absence of NHC-Borane, no polymerization was observed in the case of styrene, ${ }^{18}$ and we had previously showed that the NHC-Boranes were actually accelerating additives for the polymerization of acrylates in organic solution. ${ }^{28}$ That is to say, the reverse effect of what was observed here. 
In order to understand this, we considered the expected mechanism of the polymerization. In our established system, $\mathrm{AO}$ is first photoexcited via photon absorption. This excited state ( $\left.\mathrm{AO}^{*}\right)$ is able to transfer an electron to the disulfide, resulting in a radical anion that collapses to thiyl radical 3• and the corresponding aryl thiolate (3- , see Figure 1). Alternatively, without AO, 2 can be photocleaved to generate directly two radicals 3• (Figure 5). As stated before, this normally happens in the UV region since $\mathbf{2}$ has only a very weak absorption in the blue region. Still, formation of $3 \bullet$ is possible in our conditions, since the LEDs used consist of a sharp emission in the blue, combined to a larger emission in the yellow and red (see ESI, Figure S1). In the presence of the NHC-Borane 1, H-atom transfer to 3• ensues. In order to clarify whether that B to $\mathrm{S} \mathrm{H}$-atom transfer was still effective in water - where initiation of our emulsion polymerizations happens -, we determined several rate constants in water by Laser Flash Photolysis (LFP). The experimental setup was the same as in our previous papers, ${ }^{29,}{ }^{30}$ with the exception that the solvent was now water and the diaryldisulfide was $\mathbf{2}$.

We measured that $\mathrm{H}$-atom transfer from $\mathbf{1}$ to $\mathbf{3} \cdot$ proceeded in water with a rate constant $\mathrm{k}_{\mathrm{H}}=5 \times 10^{7} \mathrm{M}^{-1} \mathrm{~s}^{-1}$. The NHC-boryl radical 1• adds to MMA with a $\mathrm{k}_{\mathrm{add}}=2 \times 10^{7} \mathrm{M}^{-1} \mathrm{~s}^{-1} \cdot{ }^{23} \mathrm{On}$ the other hand, we could not measure a rate of addition for thiyl radical to MMA, suggesting that the corresponding rate constant is near or below the threshold of detection by LFP $\left(\sim 10^{5} \mathrm{M}^{-1} \mathrm{~s}^{-1}\right)$, although care must be exercised since the noise level is quite high due to the use of water. Nevertheless, the Ito group determined that phenylthiyl radicals add to MMA at a $\mathrm{k}_{\mathrm{add}}=3.2 \times 10^{6}$ $\mathrm{M}^{-1} \mathrm{~s}^{-1}$ in cyclohexane at $25^{\circ} \mathrm{C}$ and to styrene with a $\mathrm{k}_{\mathrm{add}}=2.0 \times 10^{7} \mathrm{M}^{-1} \mathrm{~s}^{-1}$, suggesting that $3 \bullet$ would add faster to styrene in water. ${ }^{31,32}$

The rate constant for H-transfer is slightly lower than that of the same transfer in ethylbenzene/acetonitrile $\left(1.2 \times 10^{8} \mathrm{M}^{-1} \mathrm{~s}^{-1}\right)^{33}$ but the rate constant difference still shows that all 
thiyl radicals are likely consumed by $\mathbf{1}$ in the emulsion conditions. Thus, in that case, the NHCBoryl radicals are the initiating species, while in the absence of $\mathbf{1}$, the thiyl radicals $\mathbf{3} \cdot$ are the initiating species. In order to explain why the arylthiyl radicals lead to efficient polymerization of MMA but not styrene, we considered the different steps involved in the emulsion process (Figure 5).

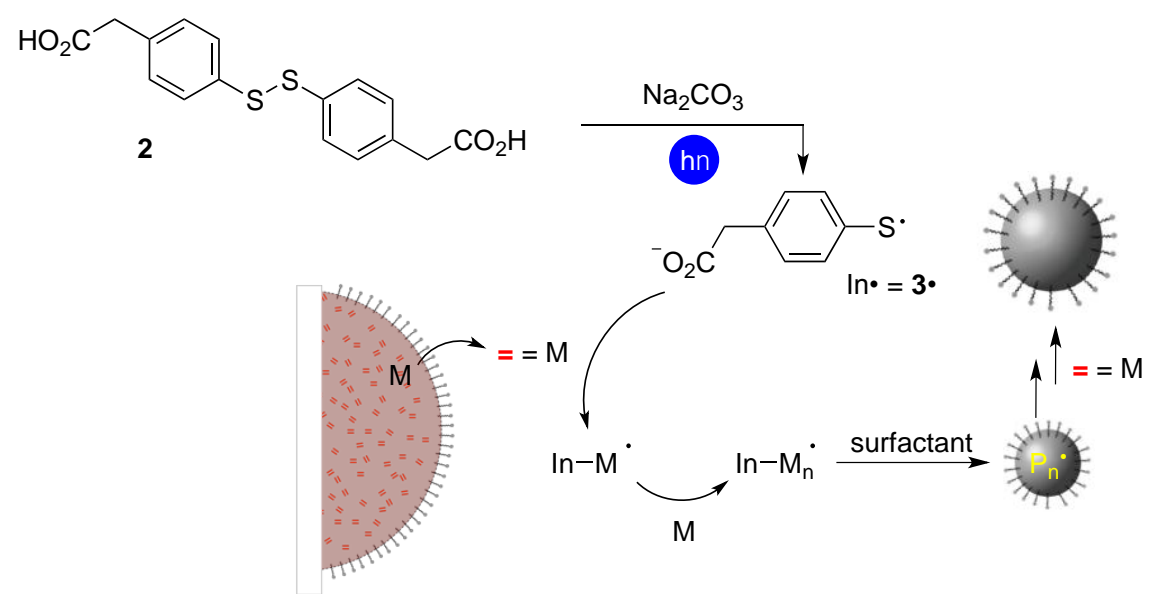

Figure 5. Mechanism of the photoinitiation of the emulsion radical polymerization by disulfide 2 alone.

First, a fraction of the monomer should be solubilized into the continuous (aqueous) phase. Second, an initiating radical (In•) should add to the first monomer molecule. Third, the addition of the initial adduct to a new monomer molecule has to proceed, until (fourth) one of these two paths happens: a) if the surfactant concentration is above $\mathrm{CMC}$, micelles are present: the oligoradical becomes hydrophobic and enters a micelle; or, b) under the $\mathrm{CMC}$, the oligoradical eventually becomes hydrophobic, recruits diluted surfactant to generate a surfactant-stabilized particle through homogeneous nucleation. In both cases, the polymer chains grow inside the objects until termination happens. Let's consider the implications of the monomer change at each stage. 
- Addition of the initiating radical (eq. 1). We could not determine the rate constants for the thiyl radical addition to the monomers in water because they are too low to be measured by LFP (see above for MMA and ref. ${ }^{18}$ for styrene).

$$
\mathrm{ArS} \bullet+\mathrm{H}_{2} \mathrm{C}=\mathrm{CH}-\mathrm{R} \rightarrow \mathrm{ArS}-\mathrm{CH}_{2}-\mathrm{CH}(\mathrm{R}) \bullet
$$

From the literature it is known that the phenylthiyl radical adds faster to styrene by almost an order of magnitude ${ }^{31}$ (see also above). For the actual rate, one has to factor in the monomer concentration, which is actually the solubility of the monomers in water. The rates for both additions are $\mathrm{r}_{\mathrm{MMA}}=\mathrm{k}_{\mathrm{add}(\mathrm{MMA})} \mathrm{x}[\mathrm{ArS} \bullet] \mathrm{x}[\mathrm{MMA}]$ and $\mathrm{r}_{\mathrm{St}}=\mathrm{k}_{\mathrm{add}(\mathrm{St})} \mathrm{x}[\mathrm{ArS} \bullet] \mathrm{x}[\mathrm{St}]$. It derives that $\mathrm{r}_{\mathrm{MMA}} / \mathrm{r}_{\mathrm{St}}=\left[\mathrm{k}_{\mathrm{add}(\mathrm{MMA})} / \mathrm{k}_{\mathrm{add}(\mathrm{St}}\right] \mathrm{x}[\mathrm{MMA}] /[\mathrm{St}]$. If the $\mathrm{k}_{\mathrm{add}}$ ratio is approx. $1 / 6$, and the solubility of MMA is 35 times higher than that of styrene (see above), thus $r_{\text {MMA }}$ is higher by at least a factor 5.

However, one has to take into consideration the reversibility of the first addition. Both of these rate constants are similar $\left(\mathrm{k}_{\text {-add(MMA })}=1.4 \times 10^{6} \mathrm{~s}^{-1}\right.$ and $\left.\mathrm{k}_{\text {-add(St) }}=4.1 \times 10^{5} \mathrm{~s}^{-131,32}\right)$, and, most importantly, lower than the addition ones. Overall, the initiation is faster in the case of MMA.

- Formation of oligoradicals (eq. 2). This stage still happens in water and it proceeds as long as the oligoradical formed remains soluble in water.

$$
\operatorname{ArS}-\mathrm{CH}_{2}-\mathrm{CH}(\mathrm{R}) \bullet+\mathrm{n} \mathrm{H}_{2} \mathrm{C}=\mathrm{CH}-\mathrm{R} \rightarrow \mathrm{ArS}-\left[\mathrm{CH}_{2}-\mathrm{CH}(\mathrm{R})\right]_{\mathrm{n}}-\mathrm{CH}_{2}-\mathrm{CH}(\mathrm{R}) \bullet
$$

We approximate the rate with that of the polymerization propagation, which is a factor of the initiating radical concentration, the monomer concentration and its $\mathrm{k}_{\mathrm{p}}$. It is difficult to measure the concentration of thiyl radicals formed by the two methods (direct photolysis and photoreduction). Given the fact that the polymerizations of both styrene with the full system and 
MMA with only the disulfide did proceed, we assume formation of the thiyl radicals is not a limiting value, with the caveat that we determined in our previous communication that it is likely that the flux of initiating radicals is somewhat slow. ${ }^{18}$ The monomer concentration is again the solubility in water of the monomers. Therefore that step is highly favoring the polymerization of MMA over that of styrene since both factors favor MMA (in particular $\mathrm{k}_{\mathrm{p}(\mathrm{MMA})} / \mathrm{k}_{\mathrm{p}(\mathrm{St})}$ close to 3 $\left.{ }^{34,35}\right)$.

- Nucleation by entrance into the micelles or self-exclusion. For the nucleation to happen, the oligoradicals have to reach a critical size. This happens after addition of a few monomer units and that number depends on the monomer. It also depends on the mechanism, as self-exclusion (i.e., homogeneous nucleation) in the absence of micelles needs more monomers in the chain to happen, relative to penetration into existing micelles. That step is not rate-determining.

To conclude, we think that the combination of a higher solubility in water of MMA and a larger $\mathrm{k}_{\mathrm{p}}$ with a rather low flux of radicals explain why the disulfide does trigger polymerization for MMA and not styrene. Indeed, the flux of radicals is likely to be too low to support a polymerization of a monomer that is not itself very rapid. In the case of styrene, there is initiation but the radicals formed likely die before leading to efficient nucleation.

We still cannot explain why the full system (that is, with initiation by the boryl radicals) is slower for the polymerization of MMA than from the direct disulfide photolysis. One possibility is that the latter forms two initiating radicals while the former forms only one. Furthermore, the former initiation relies on a three-step cascade and perhaps the system needs some time to establish an efficient nucleation. Despite this, the overall message is that MMA can be 
photopolymerized in emulsion using a very simple Type I initiator and visible light. We examined the scope of this new photo-initiating system with [2] $=5 \times 10^{-4} \mathrm{M}$ (Table 2, Figure 7). 
Table 2. Visible light emulsion photopolymerization or co-polymerizations of different monomers initiated by the water-soluble diaryldisulfide 2 .

\begin{tabular}{|c|c|c|c|c|c|c|c|c|c|}
\hline Entry $^{\mathrm{a}}$ & Monomer & Time (h) & $\begin{array}{l}\text { Conv. } \\
(\%)\end{array}$ & $\begin{array}{l}D_{\mathrm{h}} \\
(\mathrm{nm})^{\mathrm{b}}\end{array}$ & $\mathrm{PdI}^{\mathrm{b}}$ & $\mathrm{N}_{\mathrm{p}}\left(10^{17} \mathrm{~cm}^{-3}\right)^{\mathrm{b}}$ & $D_{\mathrm{n}}(\mathrm{nm})^{\mathrm{c}}$ & $D_{\mathrm{w}} / D_{\mathrm{n}}{ }^{\mathrm{c}}$ & $\begin{array}{l}\mathrm{N}_{\mathrm{p}} \\
\left(10^{17} \quad \mathrm{~cm}^{-}\right. \\
\left.{ }^{3}\right)^{\mathrm{c}}\end{array}$ \\
\hline $15^{\mathrm{d}}$ & MMA & 3.5 & 97 & 127 & 0.03 & 1.5 & 99 & 1.23 & 3.4 \\
\hline 16 & MMA & 1.4 & 100 & 100 & 0.03 & 3.3 & 70 & 1.15 & 9.3 \\
\hline $17^{\mathrm{e}}$ & MMA & 2 & 100 & 147 & 0.03 & 2.1 & 109 & 1.14 & 5.2 \\
\hline $18^{\mathrm{f}}$ & MMA & 23 & 100 & 107 & 0.08 & 2.6 & 69 & 1.34 & 10 \\
\hline 19 & BMA & 1.5 & 100 & 111 & 0.03 & 2.6 & 87 & 1.13 & 5.5 \\
\hline 20 & EHMA & 8 & 93 & 130 & 0.03 & 1.8 & 90 & 1.23 & 5.1 \\
\hline 21 & MA & 3 & 86 & 104 & 0.07 & 2.4 & 57 & 1.63 & 14.7 \\
\hline 22 & $\mathrm{BA}$ & 6.5 & 84 & 140 & 0.02 & 1.1 & 87 & 1.39 & 4.5 \\
\hline \multirow[t]{2}{*}{$23^{\mathrm{g}}$} & $\begin{array}{l}\text { MMA/St } \\
80: 20\end{array}$ & 2 & 100 & 92 & 0.04 & 4.3 & 74 & 1.12 & 8.4 \\
\hline & $\begin{array}{l}\mathrm{MMA} / \mathrm{St} \\
50: 50\end{array}$ & 2.5 & 97 & 101 & & & & & \\
\hline $24^{\mathrm{g}}$ & $\begin{array}{l}\text { MMA/St } \\
20: 80\end{array}$ & 2.5 & 100 & 89 & 0.01 & 5 & 74 & 1.08 & 8.9 \\
\hline $25^{\mathrm{g}}$ & $\begin{array}{l}\text { MMA/St } \\
10: 90\end{array}$ & 22 & 100 & 100 & 0.03 & 3.5 & 77 & 1.11 & 7.9 \\
\hline $26^{\mathrm{g}}$ & $\begin{array}{l}\text { MMA/St } \\
2: 98\end{array}$ & 36 & 88 & 124 & 0.08 & 1.6 & 88 & 1.17 & 5.4 \\
\hline $27^{\mathrm{g}}$ & $\begin{array}{l}\mathrm{MMA} / \mathrm{BA} \\
40: 60\end{array}$ & 2.8 & 85 & 100 & 0.06 & 2.9 & 80 & 1.25 & 6.3 \\
\hline
\end{tabular}

\footnotetext{
${ }^{a}$ Conditions: the monomer(s) was(were) added to the water phase containing the surfactant (SDS) and $2\left(5 \times 10^{-4} \mathrm{M}\right)$. Unless otherwise specified, the solids content was fixed at $20 \%$ and the amount of SDS was fixed at $2 \mathrm{CMC} ;{ }^{b}$ Hydrodynamic diameter, polydispersity index and number of particles determined by DLS; ${ }^{c}$ Number-average diameter, size dispersity and number of particles determined by TEM; ${ }^{d}$ concentration of SDS was $0.75 \mathrm{CMC}$; ${ }^{e}$ Solids content was $41 \% ;{ }^{f}$ Polymerization was carried out in on/off mode (see Figure 6); ${ }^{g}$ The monomer ratios in all copolymerizations are weight ratios.
} 
We first varied the SDS concentration in the homopolymerization of MMA. Below the CMC, the polymerization took longer $(3.5 \mathrm{~h}$, Table 2 , entry $15,0.75 \mathrm{CMC})$ but delivered larger (polydisperse) particles ( 100 vs. $90 \mathrm{~nm})$. Conversely, with more surfactant (2 CMC), the particles were smaller and the polymerization was again faster (entry 16), albeit no faster that at 1 CMC (See Table 1, entry 13). The solids content could be increased from 20 to $41 \%$. This resulted in a slightly slower polymerization $(2 \mathrm{~h})$ but larger particles $(\sim 110 \mathrm{~nm}$, entry 17$)$. In all cases it should be pointed out that the latexes were stable, with no coagulum. Finally, we switched on and off the light (entry 18, Figure 6). As can be seen, any "shady" region, whereby light was switched off resulted in stopping of the polymerization, which could be turned on again with light. This did not affect the conversion (100\%), nor the average particle size. The PSD however was slightly less good (compare entries 16 and 18).

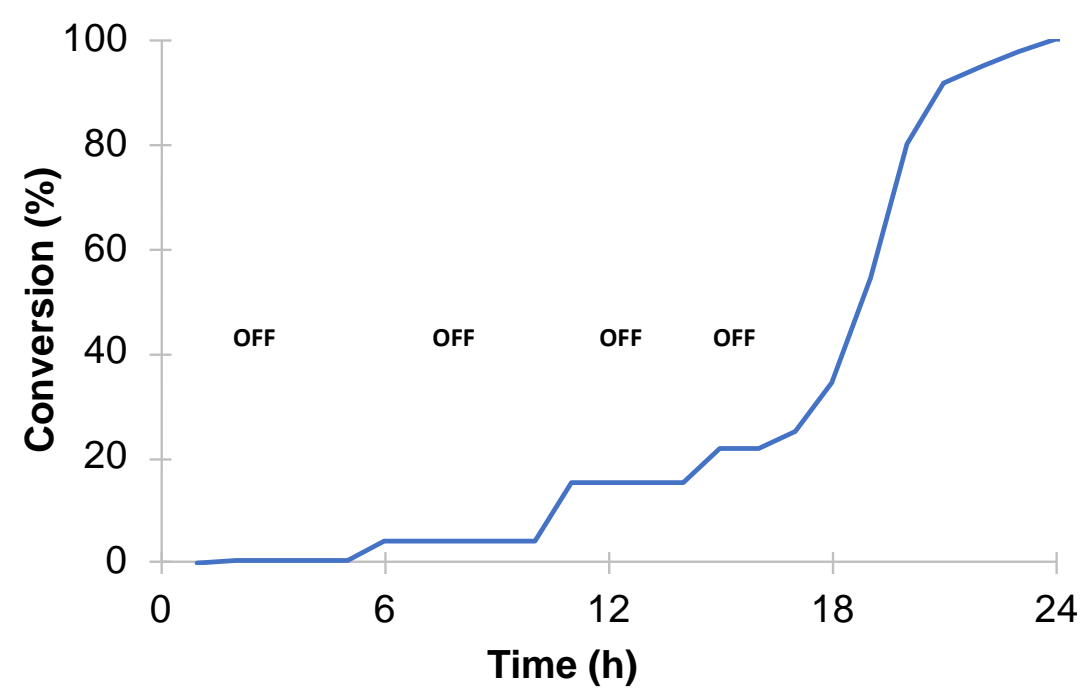

Figure 6. Conversion profile during temporal control (see Table 2, entry 18).

At this stage we considered the polymerization of other (meth)acrylate monomers, beyond MMA (Figure 7, top). As seen in Table 2, $n$-butyl methacrylate (BMA) led to an efficient 
polymerization (entry 19). The polymerization of the much less soluble 2-ethyl hexyl methacrylate (EHMA, $3.1 \mathrm{mg} \mathrm{L}^{-136}$ at $20^{\circ} \mathrm{C}$ vs. $0.36 \mathrm{~g} \mathrm{~L}^{-1}$ for BMA at $50{ }^{\circ} \mathrm{C}^{37}$ ) also proceeded smoothly albeit the conversion was a little bit lower ( $93 \%$, entry 20$)$. The average particle sizes and distributions for both EHMA and BMA were close to that observed with MMA but the polymerization of EHMA was slower ( $8 \mathrm{~h}$ vs. $1.5 \mathrm{~h}$ for BMA and MMA, respectively). Both methyl acrylate (MA, $52.5 \mathrm{~g} \mathrm{~L}^{-1}$ at $50{ }^{\circ} \mathrm{C}^{38}$ ) and $n$-butyl acrylate (BA, $0.8 \mathrm{~g} \mathrm{~L}^{-1}$ at $50{ }^{\circ} \mathrm{C}^{39}$ ) led to efficient polymerization (entries 21 and 22, respectively). The latter led to larger particles than the former, although again with a rather high PSD.

We next considered mixtures of MMA and styrene (St, entries 23-26, Table 2 and Figure 7, bottom). The more styrene in the mix, the slower the polymerization was. Interestingly, however, at $80 \% \mathrm{St}$ (in weight) the polymerization was over in $2.5 \mathrm{~h}$ (entry 24 ), while with $90 \%$ styrene the polymerization took almost one day to reach $77 \%$ conversion (entry 25 ). Also, with the exception of the last polymerization, the average particle size and the size dispersity remained constant. In the latter we observed slightly larger particles ( $88 \mathrm{vs.} 74-77 \mathrm{~nm}$ ). The conversion was also slightly less good (88\%).

The example of EHMA shows that water solubility of the monomers is not playing a significant role to explain the fact that disulfide $\mathbf{2}$ is able to photo-initiate the polymerization of MMA. Indeed, EHMA is significantly less soluble than styrene $\left(3.1 \mathrm{mg} \mathrm{L}^{-136}\right.$ vs. $0.3 \mathrm{~g} \mathrm{~L}^{-126}$ at $\left.20^{\circ} \mathrm{C}\right)$ and yet the polymerization is efficient. The monomer solubility in water certainly contributes to the overall rate though, since EHMA polymerizes much more slowly than MMA.

We venture that the main reason for the styrene/(meth)acrylate difference lies in the $\mathrm{k}_{\mathrm{p}} \mathrm{s}$ of the monomers. Indeed, at $25{ }^{\circ} \mathrm{C}$, the $\mathrm{k}_{\mathrm{p}}$ of styrene is $86 \mathrm{M}^{-1} \mathrm{~s}^{-1} 35$ vs. $323 \mathrm{M}^{-1} \mathrm{~s}^{-1}$ for MMA, ${ }^{34} 370 \mathrm{M}^{-1}$ 
$\mathrm{s}^{-1}$ for BMA ${ }^{40}$ and $501 \mathrm{M}^{-1} \mathrm{~s}^{-1}$ for EHMA. ${ }^{41}$ Therefore, even if the initial addition of the thiyl radicals in the case of the (meth)acrylates are less favorable than for styrene the adduct radicals in this last case are not conducive to formation of oligoradicals and nucleation in the case of styrene because of its lower $\mathrm{k}_{\mathrm{p}}$. That is also why the MMA/St random copolymerization proceeds even in the presence of minimal amounts of MMA. The first adduct radicals (from addition of the thiyl radical to either styrene or MMA) can add fast enough to the MMA so that fruitful nucleating oligoradicals are formed. However, below 20\% of MMA content, the polymerization is faster with the full system (including the NHC-Borane) than with only the disulfide (it reached full conversion after $6 \mathrm{~h}$ vs. $22 \mathrm{~h}$ ). Interestingly, too, the full system leads to smaller particles, and the effect is more pronounced when more MMA is in the mix $(70 \mathrm{vs} .77 \mathrm{~nm}$ for $\mathrm{MMA} / \mathrm{St}=$ $10: 90 ; 45$ vs. $74 \mathrm{~nm}$ for MMA/St = 80:20). Since the disulfide is charged, and not the NHCBorane, the thiyl radical residue can likely participate to the stabilization of the particles making them smaller.





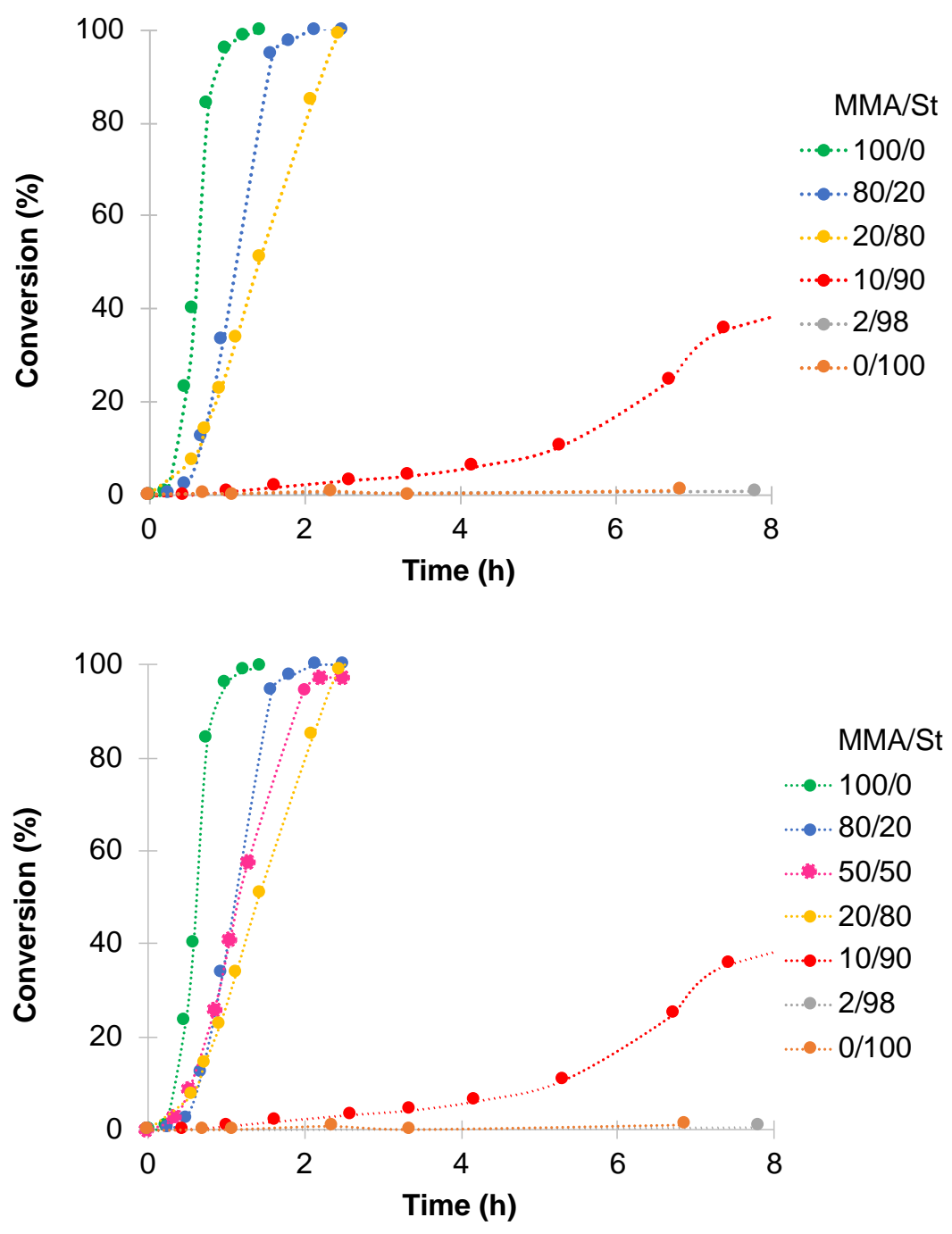

Figure 7. Conversion profiles of the emulsion photopolymerizations of different (meth)acrylate monomers (top, see Table 2, entries 15 and 19-22 for conditions) and MMA/St co-monomer ratios (w/w, bottom, see Table 2, entries 23-27 for conditions) initiated by diaryldisulfide 2 . The reference polymerization of styrene (orange curves) are taken from Ref. ${ }^{18}$

Finally, a film-forming copolymer latex (MMA/BA 40:60) could also be successfully prepared in $2.5 \mathrm{~h}$ (entry 27). The particles had an average size of $80 \mathrm{~nm}$ with a fairly large PSD and the latex led to a transparent film (Figure S4). 


\section{Conclusions}

To conclude, we have successfully extended the visible-light emulsion photopolymerization to acrylate and methacrylate monomers. For these classes of monomers, the NHC-borane-based system we initially introduced could be simplified, as the water-soluble disulfide alone was able to initiate the polymerization. With this disulfide/blue light system, MMA polymerized quite efficiently, with solids contents up to $40 \%$. The full system led to smaller particles than the simplified one (all other parameters being equal), but the latter gave slightly better particle size distributions. Compared to styrene, the particle sizes attained for MMA were generally smaller. While unsuccessful for styrene polymerization, the use of the disulfide alone gave access to a wide range of poly(meth)acrylic latexes, where the propagation rate seemed to prevail on monomer solubility. P(MMA-co-St) and film-forming P(MMA-co-BA) latexes were also produced. Further work will focus on further extending the scope of the photoemulsion process, in particular with a view to polymerize UV-sensitive materials.

\section{AUTHOR INFORMATION}

\section{Corresponding Authors}

*jacques.1alevee@uha.fr; muriel.lansalot@univ-lyon1.fr; elodie.bourgeat-lami@univ-lyon1.fr; emmanuel.1acote@univ-lyon1.fr

\section{Author Contributions}

All authors have given approval to the final version of the manuscript. 


\section{ACKNOWLEDGMENT}

We thank Université Claude Bernard Lyon 1, CNRS, CPE Lyon, UHA and ANR (grant Photo-

B) for funding of this work. DS acknowledges Université Claude Bernard and RC acknowledges

ANR for a graduate fellowship. 


\section{REFERENCES}

1. Jasinski, F.; Zetterlund, P. B.; Braun, A. M.; Chemtob, A. Photopolymerization in dispersed systems. Prog. Polym. Sci. 2018, 84, 47-88.

2. Lovell, P. A.; Schork, F. J. Fundamentals of Emulsion Polymerization. Biomacromolecules 2020.

3. Fouassier, J.-P.; Lalevée, J., Photoinitiators for Polymer Synthesis: Scope, Reactivity, and Efficiency. Wiley-VCH Verlag \& Co: Wenheim, 2012.

4. Lalevée, J.; Fouassier, J.-P., Dyes and Chromophores in Polymer Science. London, ISTE Ltd and Hoboken, John Wiley \& Sons, Inc.: 2015.

5. Tonnar, J.; Pouget, E.; Lacroix-Desmazes, P.; Boutevin, B. Synthesis of Poly(vinyl acetate)-block-poly(dimethylsiloxane)-block-poly(vinyl acetate) Copolymers by Iodine Transfer Photopolymerization in Miniemulsion. Macromol. Symp. 2009, 281, 20-30.

6. Chemtob, A.; Kunstler, B.; Croutxé-Barghorn, C.; Fouchard, S. Photoinduced miniemulsion polymerization. Colloid Polym. Sci. 2010, 288, 579-587.

7. Hoijemberg, P. A.; Chemtob, A.; Croutxé-Barghorn, C.; Poly, J.; Braun, A. M. Radical Photopolymerization in Miniemulsions. Fundamental Investigations and Technical Development. Macromolecules 2011, 44, 8727-8738.

8. Jasinski, F.; Lobry, E.; Chemtob, A.; Croutxe-Barghorn, C.; Criqui, A. Photopolymerizable Monomer Miniemulsions: Why Does Droplet Size Matter? Macromol. Chem. Phys. 2013, 214, 1669-1676. 
9. Jasinski, F.; Lobry, E.; Lefevre, L.; Chemtob, A.; Croutxe-Barghorn, C.; Allonas, X., et al. Acrylate nanolatex via self-initiated photopolymerization. J. Polym. Sci., Part A: Polym. Chem. 2014, 52, 1843-1853.

10. Lobry, E.; Jasinski, F.; Penconi, M.; Chemtob, A.; Ley, C.; Croutxe-Barghorn, C., et al. Absorption and Scattering in Concentrated Monomer Miniemulsions: Static and Dynamic Investigations. Macromol. Chem. Phys. 2014, 215, 1201-1211.

11. Tomovska, R.; de la Cal, J. C.; Asua, J. M. Miniemulsion Photo-Copolymerization of Styrene/Butyl Acrylate in a Continuous Tubular Reactor. Ind. Eng. Chem. Res. 2014, 53, 73137320.

12. Saadé, J.; Bordes, C.; Raffin, G.; Hangouët, M.; Marote, P.; Faure, K. Response surface optimization of miniemulsion: application to UV synthesis of hexyl acrylate nanoparticles. Colloid Polym. Sci. 2016, 294, 27-36.

13. Kuo, P. L.; Turro, N. J.; Tseng, C. M.; El-Aasser, M. S.; Vanderhoff, J. W. Photoinitiated polymerization of styrene in microemulsions. Macromolecules 1987, 20, 1216-1221.

14. Schauber, C.; Riess, G. Préparation de microlatex acryliques par polymérisation photochimique de solutions micellaires et de microémulsions. Makromol. Chem. 1989, 190, $725-$ 735.

15. Carver, M. T.; Dreyer, U.; Knoesel, R.; Candau, F.; Fitch, R. M. Kinetics of photopolymerization of acrylamide in AOT reverse micelles. J. Polym. Sci., Part A: Polym. Chem. 1989, 27, 2161-2177. 
16. David, G.; Özer, F.; Simionescu, B. C.; Zareie, H.; Pişkin, E. Microemulsion photopolymerization of methacrylates stabilized with sodium dodecyl sulfate and poly $(\mathrm{N}-$ acetylethylenimine) macromonomers. Eur. Polym. J. 2002, 38, 73-78.

17. Jain, K.; Klier, J.; Scranton, A. B. Photopolymerization of butyl acrylate-in-water microemulsions: Polymer molecular weight and end-groups. Polymer 2005, 46, 11273-11278.

18. Le Quéméner, F.; Subervie, D.; Morlet-Savary, F.; Lalevée, J.; Lansalot, M.; BourgeatLami, E., et al. Visible-Light Emulsion Photopolymerization of Styrene. Angew. Chem. Int. Ed. 2018, 57, 957-961.

19. Fan, W.; Tosaka, M.; Yamago, S.; Cunningham, M. F. Living Ab Initio Emulsion Polymerization of Methyl Methacrylate in Water Using a Water-Soluble Organotellurium Chain Transfer Agent under Thermal and Photochemical Conditions. Angew. Chem. Int. Ed. 2018, 57, 962-966.

20. Cao, Q.; Heil, T.; Kumru, B.; Antonietti, M.; Schmidt, B. V. K. J. Visible-light induced emulsion photopolymerization with carbon nitride as a stabilizer and photoinitiator. Polym. Chem. 2019, 10, 5315-5323.

21. Yeow, J.; Boyer, C. Photoinitiated Polymerization-Induced Self-Assembly (Photo-PISA): New Insights and Opportunities. Adv. Sci. 2017, 4, 1700137.

22. Tkachenko, V.; Matei Ghimbeu, C.; Vaulot, C.; Vidal, L.; Poly, J.; Chemtob, A. RAFTphotomediated PISA in dispersion: mechanism, optical properties and application in templated synthesis. Polym. Chem. 2019, 10, 2316-2326 
23. Tehfe, M.-A.; Monot, J.; Malacria, M.; Fensterbank, L.; Fouassier, J.-P.; Curran, D. P., et al. A Water-Compatible NHC-Borane: Photopolymerizations in Water and Rate Constants for Elementary Radical Reactions. ACS Macro Lett. 2012, 1, 92-95.

24. Lalevée, J.; Blanchard, N.; Tehfe, M.-A.; Peter, M.; Morlet-Savary, F.; Gigmes, D., et al. Efficient dual radical/cationic photoinitiator under visible light: a new concept. Polym. Chem. 2011, 2, 1986-1991.

25. Ballard, M. J.; Napper, D. H.; Gilbert, R. G. Kinetics of emulsion polymerization of methyl methacrylate. J. Polym. Sci. Polym. Chem. Ed. 1984, 22, 3225-3253.

26. Lane, W. H. Determination of Solubility of Styrene in Water and of Water in Styrene. Ind. Eng. Chem., Anal. Ed. 1946, 18, 295-296.

27. Fast, D. E.; Lauer, A.; Menzel, J. P.; Kelterer, A.-M.; Gescheidt, G.; Barner-Kowollik, C. Wavelength-Dependent Photochemistry of Oxime Ester Photoinitiators. Macromolecules 2017, $50,1815-1823$.

28. Lalevée, J.; Telitel, S.; Tehfe, M. A.; Fouassier, J. P.; Curran, D. P.; Lacôte, E. NHeterocyclic Carbene Boranes Accelerate Type I Radical Photopolymerizations and Overcome Oxygen Inhibition. Angew. Chem. Int. Ed. 2012, 51, 5958-5961.

29. Tehfe, M.-A.; Makhlouf Brahmi, M.; Fouassier, J.-P.; Curran, D. P.; Malacria, M.; Fensterbank, L., et al. N-Heterocyclic Carbenes-Borane Complexes: A New Class of Initiators for Radical Photopolymerization. Macromolecules 2010, 43, 2261-2267. 
30. Tehfe, M.-A.; Monot, J.; Brahmi, M. M.; Bonin-Dubarle, H.; Curran, D. P.; Malacria, M., et al. N-Heterocyclic carbene-borane radicals as efficient initiating species of photopolymerization reactions under air. Polym. Chem. 2011, 2, 625-631.

31. Ito, O.; Matsuda, M. Evaluation of addition rates of the thiyl radicals to vinyl monomers by flash photolysis. 2. Substituent effect on addition of substituted benzenethiyl radicals to methyl methacrylate or styrene. J. Am. Chem. Soc. 1979, 101, 5732-5735.

32. Ito, O. Flash photolysis study on reversible addition reactions of thiyl radicals. Res. Chem.Intermed. 1995, 21, 69-93.

33. Pan, X.; Lacôte, E.; Lalevée, J.; Curran, D. P. Polarity Reversal Catalysis in Radical Reductions of Halides by N-Heterocyclic Carbene Boranes. J. Am. Chem. Soc. 2012, 134, 56695674.

34. Beuermann, S.; Buback, M.; Davis, T. P.; Gilbert, R. G.; Hutchinson, R. A.; Olaj, O. F., et al. Critically evaluated rate coefficients for free-radical polymerization, 2.. Propagation rate coefficients for methyl methacrylate. Macromol. Chem. Phys. 1997, 198, 1545-1560.

35. Buback, M.; Gilbert, R. G.; Hutchinson, R. A.; Klumperman, B.; Kuchta, F.-D.; Manders, B. G., et al. Critically evaluated rate coefficients for free-radical polymerization, 1. Propagation rate coefficient for styrene. Macromol. Chem. Phys. 1995, 196, 3267-3280.

36. Product Information - VISIOMER® EHMA from Evonik. March 2020.

37. Halnan, L. F.; Napper, D. H.; Gilbert, R. G. A study of the kinetics of the emulsion polymerization of butyl methacrylate. J. Chem. Soc., Faraday Trans. 1 1984, 80, 2851-2865. 
38. van Doremaele, G. H. J.; Schoonbrood, H. A. S.; Kurja, J.; German, A. L. Copolymer composition control by means of semicontinuous emulsion copolymerization. J. Appl. Polym. Sci. 1992, 45, 957-966.

39. Capek, I.; Barton, J.; Ordinova, E. Emulsion polymerization of butyl acrylate. Chem. Zvesti 1984, 38, 803-822.

40. Beuermann, S.; Buback, M.; Davis, T. P.; Gilbert, R. G.; Hutchinson, R. A.; Kajiwara, A., et al. Critically evaluated rate coefficients for free-radical polymerization, 3. Propagation rate coefficients for alkyl methacrylates. Macromol. Chem. Phys. 2000, 201, 1355-1364.

41. Hutchinson, R. A.; Beuermann, S.; Paquet, D. A.; McMinn, J. H. Determination of FreeRadical Propagation Rate Coefficients for Alkyl Methacrylates by Pulsed-Laser Polymerization. Macromolecules 1997, 30, 3490-3493. 